\title{
Detection of Toxoplasma gondii Infections using Virus- Like Particles Displaying T. gondii ROP4 Antigen
}

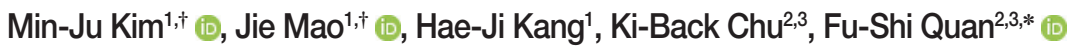 \\ ${ }^{1}$ Department of Biomedical Science, Graduate School, Kyung Hee University, Seoul 02447, Korea; ²Department of Medical Zoology, School of \\ Medicine, Kyung Hee University, Seoul 02447, Korea; ${ }^{3}$ Medical Research Center for Bioreaction to Reactive Oxygen Species and Biomedical \\ Science Institute, School of Medicine, Graduate School, Kyung Hee University, Seoul 02447, Korea
}

\begin{abstract}
Toxoplasma gondii ME49 infections are typically diagnosed by serological tests. However, serological diagnosis of $\mathrm{RH}$ strain-induced toxoplasmosis remains unknown. In order to develop seradiagnosis of above 2 kinds of infections, we generated recombinant virus-like particles (VLPs) displaying the $T$. gondii rhoptry protein 4 (ROP4) and evaluated their potential in $T$. gondii ME49 or RH strain infection diagnostics. Mice were orally infected with either the tachyzoites of $T$. gondii $(\mathrm{RH})$ or cysts of T. gondii (ME49) at various dosages, and sera were collected at regular intervals. ELISA-based serological tests were performed to assess IgG, IgM, and IgA antibody responses against ROP4 VLP antigen and tissue lysate antigen (TLA). Compared to TLA, IgG, IgM, and IgA levels to ROP4 VLP antigen were significantly higher in the sera of $T$. gondii RH-infected mice 1 and 2 week post-infection (PI). T. gondii-specific $\lg G$ antibody was detected at 1, 2, 4, and 8 week PI in the T. gondii ME49-infected mice with infection dose-dependent manner. These results indicated that the ROP4 VLP antigen was highly sensitive antigens detecting T. gondii RH and ME49 antibodies at an early stage.
\end{abstract}

Key words: Toxoplasma gondii, ELISA, rhoptry protein 4, virus-like particle, IgG

\section{INTRODUCTION}

Toxoplasma gondii, the causative agent of toxoplasmosis, is a parasite capable of evading both phagocytic and non-phagocytic cells of warm-blooded vertebrates, and approximately a third of the world's population are estimated to be affected by these pathogens. Their infection can have fatal consequences in pregnant women or immunocompromised individuals [1]. Therefore, T. gondii is a pathogenic protozoan organism of global importance [1]. T. gondii infections can be subdivided into acute and chronic stages, which are characterized by the rapid growth of tachyzoites and slow-growing cyst formations predominantly in the brain and musculature. There are 3 distinct clonal lineages of $T$. gondii and these are classified as type I (RH strain), type II (ME49), or type III based on the parasite's virulence. While type II and III strains are relatively avirulent and can establish chronic infections, type I strains are highly virulent and uniformly lethal in mice [2,3]. To successfully

- Received 7 October 2021, revised 8 December 2021, accepted 8 December 2021.

*Corresponding author (fsquan@khu.ac.kr)

${ }^{\dagger}$ These authors contributed equally to this work.

(c) 2021, Korean Society for Parasitology and Tropical Medicine

This is an Open Access article distributed under the terms of the Creative Commons Attribution Non-Commercial License (https://creativecommons.org/licenses/by-nc/4.0) which permits unrestricted non-commercial use, distribution, and reproduction in any

medium, provided the original work is properly cited. treat and manage toxoplasmosis patients, as well as estimating disease prevalence, economic loss avoidance, food safety risk evaluation, and establishing epidemic prevention policies at a national level, developing an effective T. gondii diagnostic method for both humans and animals is necessary [4].

Although various direct detection methods are available, such as bioassay, microscopy, or molecular-based assays, these methods are reported to be time-consuming, costly, and possess limited sensitivity. By contrast, multiple serologic tests including indirect haemagglutination test (IHAT), modified agglutination test (MAT), latex agglutination test (LAT), indirect fluorescent antibody test (IFAT), and enzyme-linked immunosorbent assay (ELISA) are more optimized and practical. ELI$\mathrm{SA}$, in particular, is widely utilized for its convenience in antigen-specific antibody response detection across various laboratories $[5,6]$. However, test performance depends mostly on diagnostic antigens. While most conventional tests used today are based on the T. gondii tachyzoite antigens, standardizing this method is difficult due to the presence of non-parasitic components from eukaryotic host cells. Consequently, numerous studies have reported the acquisition of false-positive results along with poor specificity and sensitivity for $T$. gondii for this method [7]. In the past decade, multiple recombinant antigens with serodiagnostic potential were identified, which 
includes dense granule proteins (GRA) [8-10], the surface antigens (SAG) $[5,11]$, microneme proteins (MIC), cyst matrix antigen (MAG1), apical membrane antigen (AMA) [12], and the rhoptry proteins (ROP) $[13,14]$. In the aforementioned studies, recombinant protein antigens were tested using the sera acquired from T. gondii-infected humans and animals. To date, not a single study investigated the relationship between $\mathrm{RH}$ or ME49 strain infection dose and the resulting antibody induction in murine models. Rather, in majority of the studies performing recombinant antigen-based ELISA using human $T$. gondii infection sera, several variables remain unknown such as the duration post-infection, infection dose, and the strain information. Additionally, most studies only assessed IgG response against recombinant protein along with either IgM or IgA. None of them evaluated the responses of all 3 antibody isotypes under identical experimental conditions.

ROP4, belonging to the ROP2 protein family, is expressed at all 3 infective stages of the T. gondii, which includes the tachyzoite, bradyzoite, and the sporozoite. Previously, we have demonstrated that ROP4-expressing VLPs were highly immunogenic and as such, these could be exploited as a potential $T$. gondii diagnostic marker [15].

In the present study, sera of T. gondii RH and ME49-infected mice were collected and used to evaluate the diagnostic antigen potential of $T$. gondii ROP4 VLPs by comparing the IgG, IgM, and IgA antibody responses with those of TLA. Findings herein suggest that ROP4 VLP antigen were highly sensitive and enables the detection of $T$. gondii at an early stage of infection, thus signifying their potential for further development.

\section{MATERIALS AND METHODS}

\section{Ethics statement}

Seven-week-old female BALB/c mice were purchased from NARA Biotech (Seoul, Korea) and maintained under specificpathogen-free conditions. All animal experiments were carried out in accordance with the regulations of the Kyung Hee University IACUC (institutional approval number: KHSASP-20165).

\section{Parasites and cells}

Parasites and cells were maintained and harvested as described previously [4]. Briefly, mice were intraperitoneally infected with $T$. gondii RH strain and ME49 strains. Tachyzoites of RH strain were separated from peritoneal fluids at 5 days PI and resuspended in phosphate-buffered saline (PBS), which were subsequently purified by discontinuous Percoll density gradient centrifugation. ME49 cysts were isolated from the brains of mice at 4 week PI. Spodoptera frugiperda (Sf9) cells were cultured and maintained at $27^{\circ} \mathrm{C}$ in spinner flasks at $130-135$ rpm in serum-free SF900II media (Invitrogen, Carlsbad, California, USA) supplemented with $0.1 \%$ penicillin [16].

\section{Generation of recombinant baculoviruses and VLPs}

Recombinant baculoviruses (rBVs) and VLPs expressing ROP4 (accession No. EU047558) and M1 (accession No. EF4 67824) were prepared as described previously [15]. Briefly, total RNAs of T. gondii RH strain and influenza A virus (A/ PR8/34) were extracted and reverse transcribed for cDNA synthesis. T. gondii ROP4 and influenza M1 genes were amplified by polymerase chain reaction (PCR) and subsequently cloned into the pFastBac vector. Afterward, genes were transformed using DH10Bac competent cells and positive clones were used to generate rBVs. Sf9 cells were co-infected with the M1-rBVs and ROP4-rBVs to generate ROP4 VLPs. Afterward, VLPs were purified through a discontinuous sucrose gradient centrifugation and stored at $-80^{\circ} \mathrm{C}$ until use as described previously [12, 15].

\section{Preparation of tachyzoites lysate antigen (TLA)}

TLA was prepared from the harvested T. gondii RH tachyzoites. Briefly, tachyzoites were sonicated and centrifuged at 2,000 rpm for $10 \mathrm{~min}$ at $4^{\circ} \mathrm{C}$. Supernatant as TLA was carefully collected and protein concentration was determined using the QuantiPro BCA Assay Kit (Sigma-Aldrich, St. Louis, USA) $[15,17]$. Samples were stored at $-20^{\circ} \mathrm{C}$ until use.

\section{Characterization of VLPs}

Toxoplasma gondii ROP4 and influenza M1 proteins were characterized by western blot. After the separated proteins were transferred onto a nitrocellulose membrane, the membranes were blocked and probed with either $T$. gondii-specific polyclonal antibody or influenza virus anti-M1 monoclonal antibody (Abcam, Cambridge, UK) [19]. Images were acquired using Bio-High voltage EM system (JEM-1400 Plus at $120 \mathrm{kV}$ and JEM-1000BEF at 1,000 kV, JEOL Ltd., Tokyo, Japan) at Korea Basic Science Institute.

\section{Animal experiments}

Mice ( $\mathrm{n}=6$ per group) were orally infected with $5 \times 10^{3}, 1 \times 10^{4}$, 
and $5 \times 10^{4}$ tachyzoites of $T$. gondii RH strain. For ME49, mice were infected with 10, 50,150, or 300 cysts through the oral route. For RH-infected mice, blood samples were collected at 1 and 2 week PI. Blood samples of ME49-infected mice were collected at 1,2, 4, and 8 week PI. Blood samples were collected from the retro-orbital plexus puncture and the sera were stored at $-20^{\circ} \mathrm{C}$ until use.

\section{ELISA on antibody production in the mice infected with T. gondii RH or ME49 strain using ROP4 VLPs as antigen} Using TLA or the ROP4 VLPs as antigen, IgG, IgA, and IgM responses were measured by ELISA as described previously [20]. The 96 wells in immunoplates (SPL Life Sciences, Pocheon, Korea) were coated with either TLA or ROP4 VLPs at a concentration of $4 \mu \mathrm{g} / \mathrm{ml}$ in $0.05 \mathrm{M}$ carbonate coating buffer (pH 9.6) and incubated overnight at $4^{\circ} \mathrm{C}$. Sera collected from mice were added at 1:100 dilution in PBS into well. After incubating for $1 \mathrm{hr}$ at $37^{\circ} \mathrm{C}, 100 \mu \mathrm{l} /$ well of horseradish peroxidase (HRP)-conjugated goat anti-mouse IgG, IgA or IgM (Southern Biotech, Birmingham, Alabama, USA) 1:2,000 in PBS was added. A substrate buffer containing o-phenylenediamine and $\mathrm{H}_{2} \mathrm{O}_{2}$ was added and the reaction was stopped by adding $\mathrm{H}_{2} \mathrm{SO}$. Absorbance values were measured at $492 \mathrm{~nm}$ using $\mathrm{EZ}$ Read 400 (Biochrom Ltd., Cambridge, UK) microplate reader.

\section{Statistical Analysis}

Data were statistically compared using GraphPad Prism version 5.0 (San Diego, California, USA) through the unpaired Student's t-test or one-way analysis of variance (ANOVA) with Tukey's post hoc test. In all cases, a difference were considered statistically significant when $P$-value was smaller than 0.05 . All data were presented as mean $\pm S \mathrm{~S}$.

\section{RESULTS}

\section{Characters of $T$. gondii ROP4 VLPs}

PCR-amplified T. gondii ROP4 gene was cloned into the pFastBac vector as indicated (Supplementary Fig. S1A, B). Baculoviruses expressing the ROP4 were comfirmed (Fig. 1A) by western blot using anti-T. gondii polyclonal antibodies. The spherical morphology of VLPs and the expression of ROP4 antigen spikes on their surface were confirmed by TEM (Fig. 1B).
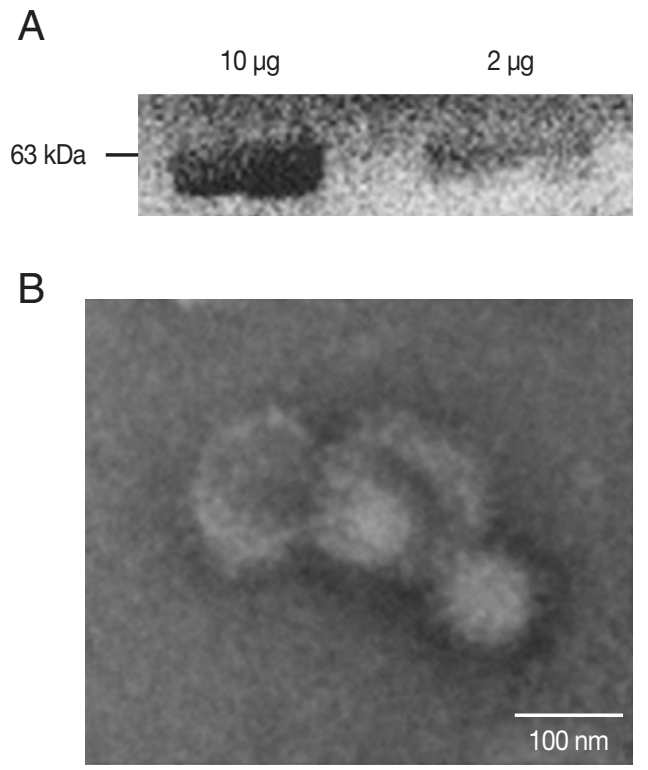

Fig. 1. Characterization of ROP4 antigen. For western blot, a total of 10 and $2 \mu \mathrm{g}$ of ROP4 VLP antigen were loaded into each lane. (A) Polyclonal mouse anti-T. gondii antibody was used to confirm the presence of $T$. gondii ROP4 protein (63 kD). (B) A transmission electron micrograph shows influenza virus-like morphology of ROP4 VLPS.

Sera of $T$. gondii $\mathrm{RH}$-infected mice strongly interacts with the ROP4 VLP antigen

Compared to the TLA antigen, significantly higher IgG responses were detected when sera were reacted with the ROP4 VLPs irrespective of the T. gondii RH infection dose (Fig. 2A-C). The antibody response trends were similar for all infection doses, with a drastic increase in IgG response at 1 week PI, followed by a marginal increase in antibody by 2 week PI. A similar trend was observed in IgM responses. IgM antibody responses appeared in a dose-dependent manner. T. gondii-specific IgM response was much greater in the $5 \times 10^{4}$ tachyzoite-infected mice sera than those from $5 \times 10^{3}$ and $1 \times 10^{4}$ infection groups (Fig. 3A-C). This was the case for IgA response, as indicated by drastically high level of IgA antibody production in $5 \times 10^{4}$ tachyzoites group (Fig. 4A-C). Importantly, ROP4 VLPs detected IgG, IgM, and IgA antibodies at 1 week PI with T. gondii RH strain, implying that ROP4 VLPs can be employed to diagnose T. gondii RH infection at the early stage.

\section{Sera of $T$. gondii ME49-infected mice strongly reacts with} the ROP4 VLP antigens

Compared to the TLA antigen, IgG levels were significantly higher in the ROP4 VLP-coated plates, irrespective of the 

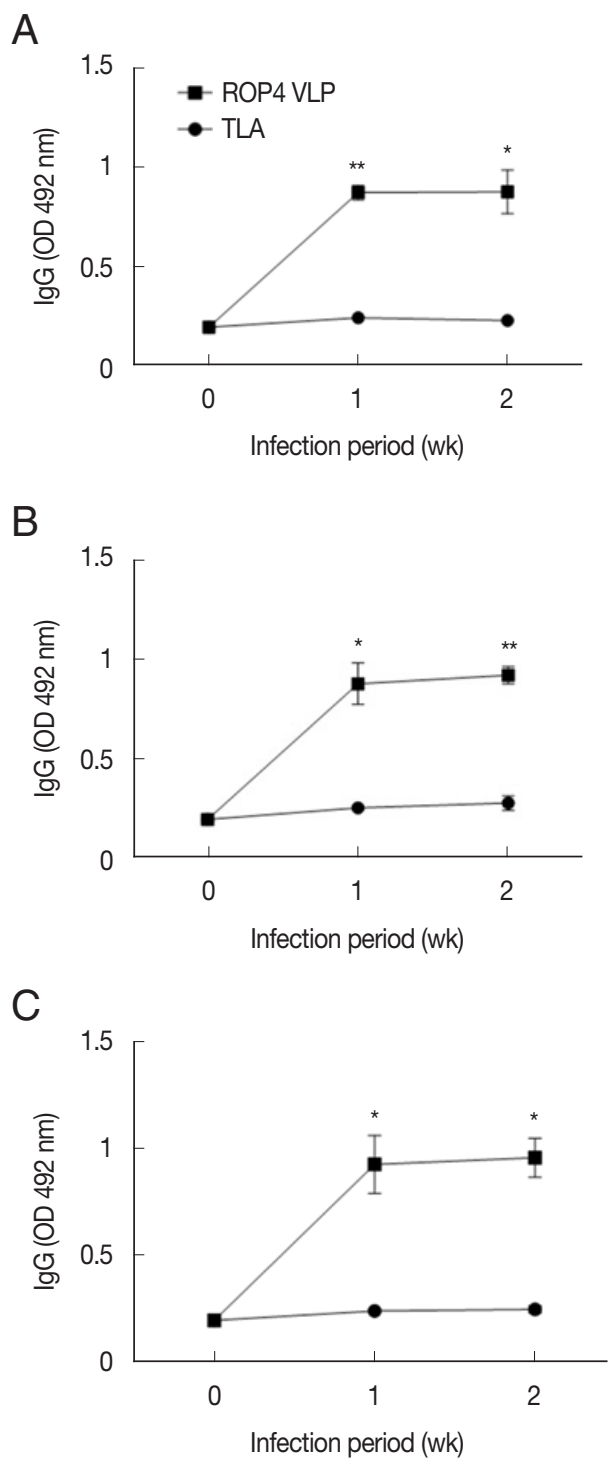

Fig. 2. IgG levels in sera of mice infected with $T$. gondii $\mathrm{RH}$ strain. Mouse sera were assessed for IgG responses by ELISA using ROP4 virus-like particles (VLPS) or tissue lysate antigens (TLA). IgG antibody responses elicited from 3 different infection doses were measured. (A) $5 \times 10^{3} \mathrm{RH}$ tachyzoites. (B) $1 \times 10^{4} \mathrm{RH}$ tachyzoites. (C) $5 \times 10^{4} \mathrm{RH}$ tachyzoites. ${ }^{\star} P<0.05$, ${ }^{\star \star} P<0.01$.

ME49 infection dose at all time points (Fig. 5A-D). Compared to low infection dose (10 and 50 cysts), antibody production was noticeably high in 150 and 300 cysts groups. Specifically, at 1 week PI, IgG antibody production increased strongly with correlation to infection dose. These results indicate that ROP4 VLP antigen can also be used to detect early stage T. gondii ME49 infection.
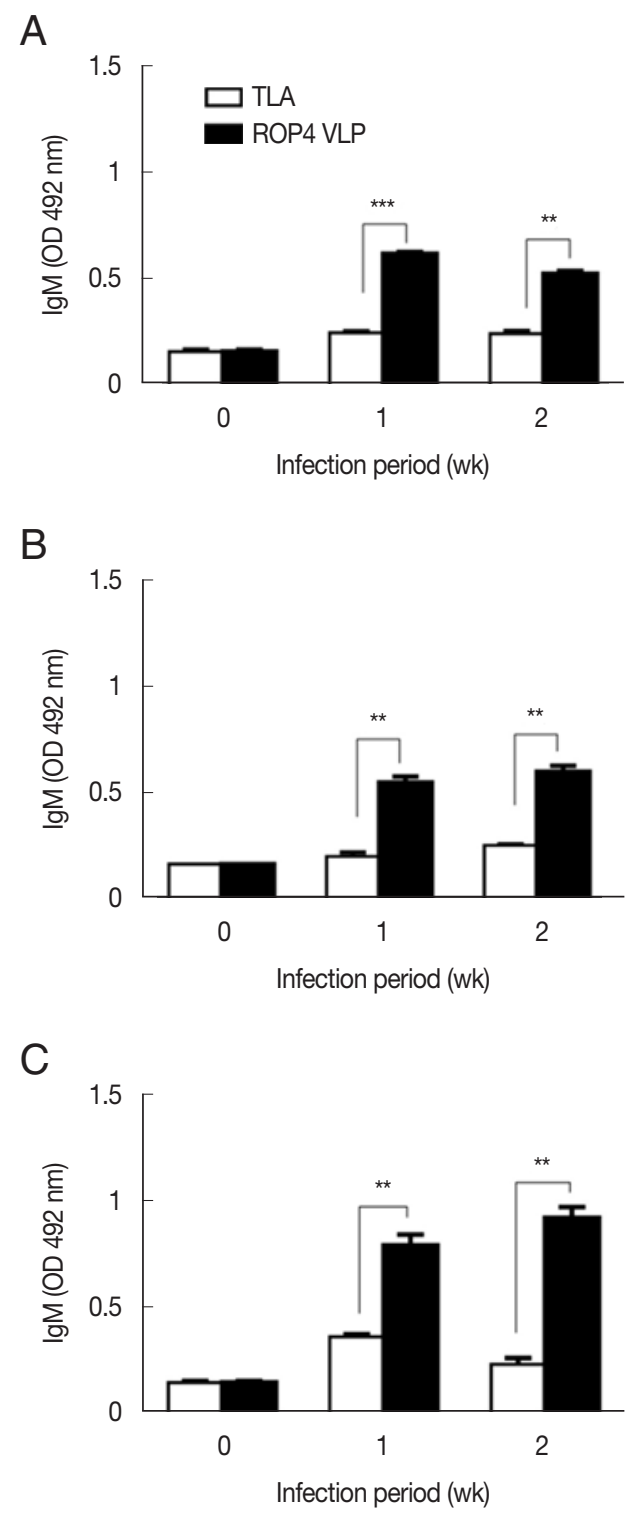

Fig. 3. IgM responses in sera of mice infected with $T$. gondii $\mathrm{RH}$ strain. IgM antibody responses were assessd by ELISA using ROP4 VLP antigen and TLA. (A) $5 \times 10^{3} \mathrm{RH}$ tachyzoites. (B) $1 \times 10^{4} \mathrm{RH}$ tachyzoites. (C) $5 \times 10^{4} \mathrm{RH}$ tachyzoites. ${ }^{*} P<0.05$, ${ }^{\star \star} P<0.01,{ }^{\star \star \star} P<0.001$.

\section{DISCUSSION}

In the present study, we evaluated the use of VLP antigen for the serodiagnosis of toxoplasmosis induced by $T$. gondii $\mathrm{RH}$ or ME49 infection in mice. Our findings revealed that compared to the conventional TLA antigen, ROP4 VLP antigen can be used as recombinant protein antigens to determine T. gondii RH or ME49 infections with significantly improved sensitivity.

T. gondii RH is highly pathogenic. Consequently, intraperito- 
A

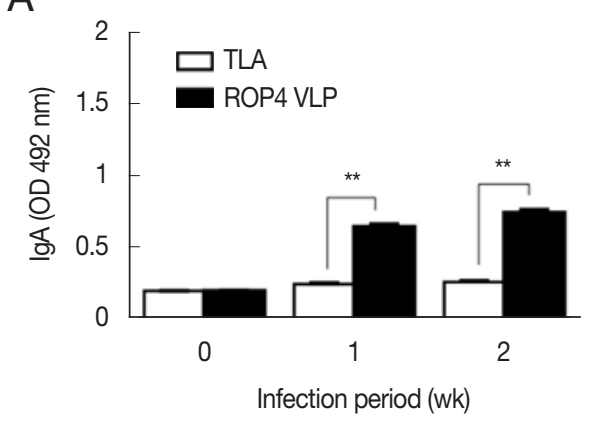

B

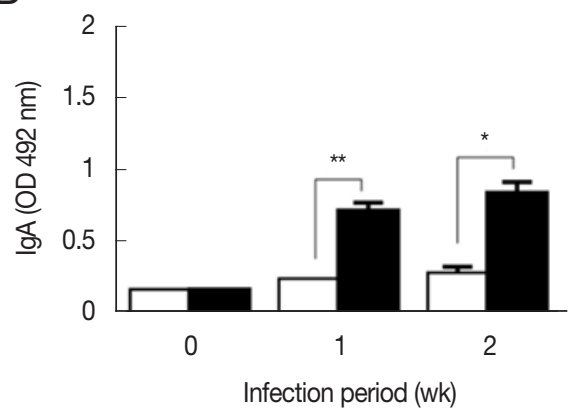

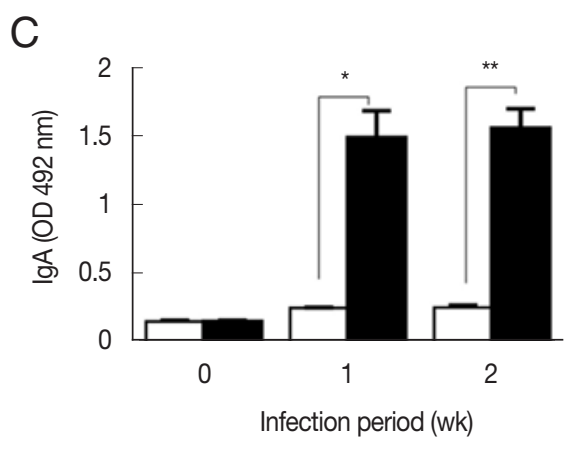

Fig. 4. IgA responses in sera of the mice infected with $T$. gondii RH strain. ROP4 VLPs or TLA were used as coating antigens in ELISA. (A) $5 \times 10^{3} \mathrm{RH}$ tachyzoites. (B) $1 \times 10^{4} \mathrm{RH}$ tachyzoites. (C) $5 \times 10^{4} \mathrm{RH}$ tachyzoites. ${ }^{*} P<0.05,{ }^{* *} P<0.01$.

A

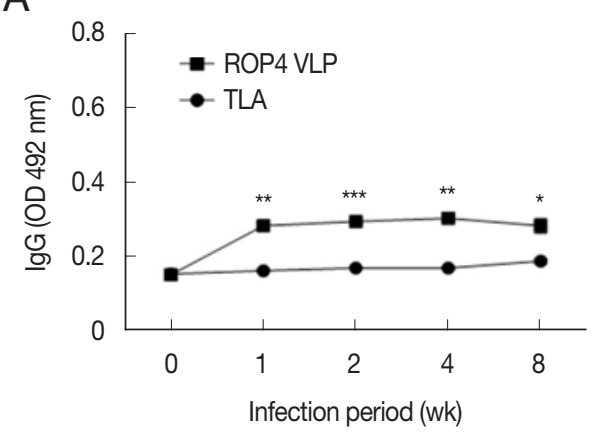

C

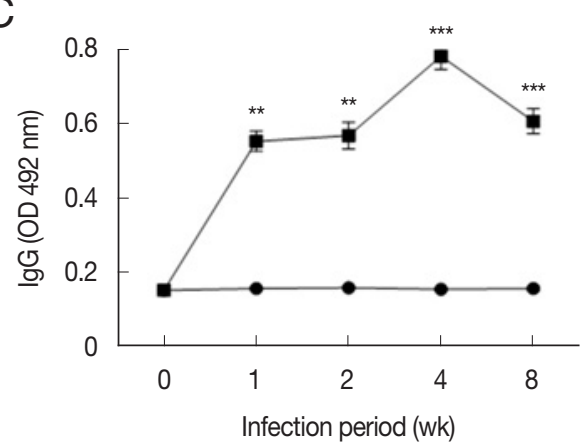

B
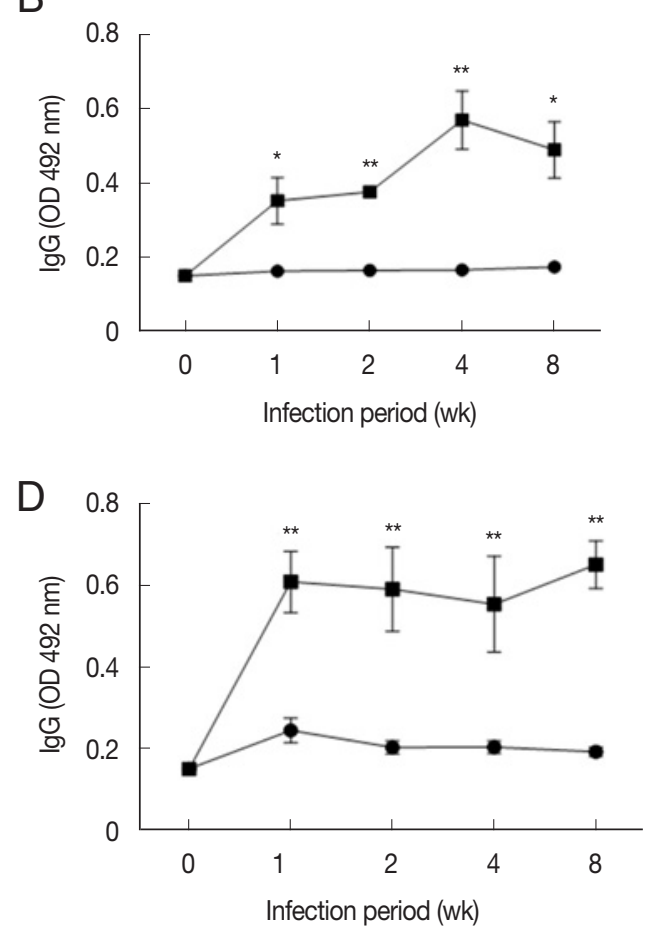

Fig. 5. IgG responses in sera of the mice infected with T. gondii ME49 strain. ROP4 VLPS or TLA were used as coating antigens in ELISA. (A) 10, (B) 50, (C) 150, or (D) 300 cysts of T. gondii ME49. ${ }^{*} P<0.05,{ }^{\star *} P<0.01$, ${ }^{\star \star *} P<0.001$. 
neally infected naïve mice usually die within 6 days and renders antibody response detection quite problematic [21,22]. To determine the antibody response induced by $T$. gondii $\mathrm{RH}$ infection, in the present study, mice were orally infected with various doses of $T$. gondii $\mathrm{RH}$ tachyzoites and we found that mice survived over 2 weeks, even when infected with $5 \times 10^{3}$, $1 \times 10^{4}$, or $5 \times 10^{4}$ tachyzoites. This enabled serum collection at 1 and 2 week PI, and the reactivities of ROP4 VLP antigen to the murine sera were detected. We found that ROP4 VLP antign can detect RH infection by significantly increased IgG, IgM, and IgA antibody responses at all measured time points whereas TLA could not, thereby suggesting the use of ROP4 VLP antigen as a recombinant protein in a serologic test of $T$. gondii RH infection.

Antibody kinetics differ greatly between each antibody isotypes, and this unique pattern seems to be dictated by the time after infections [23]. In general, serum levels of IgM increase during the earliest stage of infection followed by IgA, and the appearance of IgG occurs much later than IgM and IgA $[24,25]$. Although all of the above antibodies were elicited during the first week upon reaction with the ROP4 VLP antigen, such was not the case for antibody reaction with the TLA antigen at 1 and 2 week PI. ELISA was widely used across various laboratories as a primary diagnostic tool for $T$. gondii infection for a long time [27-30]. However, it is worth mentioning that both the infection period and dosage of experimental animals in those studies were uncertain. The high sensitivity demonstrated by the TLA ELISA could be resulted from high antibody levels produced with large infection dose, prolonged or even multiple infections. Here, we clarified that in the early stage of RH strain infections, ROP4 VLP antigen might be more suitable than TLA as a diagnostic antigen.

Toxoplasma gondii ME49, unlike the RH strain, results in chronic toxoplasmosis and is relatively avirulent $[1,30]$. Based on the review of Elsheikha et al. [24], levels of IgG peaks after IgM and IgA at approximately 4 to 8 week PI. In the serodiagnosis of IgM and IgA, we have neither found a representative correlation between infection dosages and response levels nor between time points and that (data not shown). Among studies focusing on detecting IgG responses in mice followed by ME49 cyst infections [31-34], the lowest infection dose was 20 cysts and the earliest time when IgG responses were detected was at 10 days PI. No studies have made experimental animals infected by as few as 10 cysts and no studies successfully detected IgG antibody as early as 1 week PI. Notably, in the pres- ent study, mice were infected with cysts of $T$. gondii ME49 at dosages of 10, 50, 150, and 300 cysts. At all infection doses, ROP4 VLP antigen showed higher IgG antibody responses compared to TLA antigen at 1, 2, 4, and 8 week PI, indicating that antibody induction from even a very low infectious dose can be detected using ROP4 VLP antigen. Importantly, we found that at higher infectious dosage (150 and 300 cysts), ROP4 VLP antigen showed higher IgG antibody responses as early as 1 week PI, which was not reported by using other recombinant proteins [12].

Taken together, this is the first report on application of the $T$. gondii ROP4 VLP as a coating antigen of ELISA diagnosis in mice. It was found that ROP4 VLP antigen detected T. gondii RH or ME49 infections as early as 1 week PI. Given their sensitivity and convenience, we suggest that ROP4 VLP antigen be a potential candidate for diagnosing both T. gondii RH and ME49 infections.

\section{ACKNOWLEDGMENT}

This research was supported by the National Research Foundation of Korea (NRF) (2018R1A6A1A03025124), the Ministry of Health \& Welfare, Republic of Korea (HV20C0085, HV20C0142).

\section{CONFLICT OF INTEREST}

We declare that the research was conducted without any commercial or financial relationships that could be construed as influencing the position presented in this manuscript.

\section{REFERENCES}

1. Halonen SK, Weiss LM. Neuroparasitology and Tropical Neurology: Chapter 8. Toxoplasmosis. Handbook of Clinical Neurology. Amsterdam, The Netherlands. Elsevier. 2013, pp 125-145.

2. Yarovinsky F. Toll-like receptors and their role in host resistance to Toxoplasma gondii. Immunol Lett 2008; 119: 17-21. https://doi. org/10.1016/j.imlet.2008.05.007

3. Howe DK, Sibley LD. Toxoplasma gondii comprises three clonal lineages: correlation of parasite genotype with human disease. J Infect Dis 1995; 172: 1561-1566. https://doi.org/10.1093/infdis/ 172.6.1561

4. Lee SH, Kang HJ, Lee DH, Quan FS. Protective immunity induced by incorporating multiple antigenic proteins of Toxoplasma gondii into influenza virus-like particles. Front Immunol 2019; 9: 3073. https://doi.org/10.3389/fimmu.2018.03073 
5. Hosseininejad M. Evaluation of an indirect ELISA using a tachyzoite surface antigen SAG1 for diagnosis of Toxoplasma gondii infection in cats. Exp Parasitol 2012; 132: 556-560. https:// doi.org/10.1016/j.exppara.2012.09.009

6. Lind P, Haugegaard J, Wingstrand A, Henriksen SA. The time course of the specific antibody response by various ELISAs in pigs experimentally infected with Toxoplasma gondii. Vet Parasitol 1997; 71: 1-15. https://doi.org/10.1016/S0304-4017(97)00010-1

7. Pishkari S, Shojaee S, Keshavarz H, Salimi M, Mohebali M. Evaluation of Toxoplasma gondii soluble, whole and excretory/secretary antigens for diagnosis of toxoplasmosis by ELISA test. J Parasit Dis 2017; 41: 289-291. https://doi.org/10.1007/s12639-0160794-1

8. Sun X, Wang Z, Li J, Wei F, Liu Q. Evaluation of an indirect ELISA using recombinant granule antigen GRA1, GRA7 and soluble antigens for serodiagnosis of Toxoplasma gondii infection in chickens. Res Vet Sci 2015; 100: 161-164. https://doi.org/10.1016/ j.rvsc.2015.04.011

9. Golkar M, Rafati S, Abdel-Latif MS, Brenier-Pinchart M, FrickerHidalgo H, Sima BK, Babaie J, Pelloux H, Cesbron-Delauw M, Mercier C. The dense granule protein GRA2, a new marker for the serodiagnosis of acute Toxoplasma infection: comparison of sera collected in both France and Iran from pregnant women. Diagn Microbiol Infect Dis 2007; 58: 419-426. https://doi.org/10.1016/ j.diagmicrobio.2007.03.003

10. Wang Z, Ge W, Huang S, Li J, Zhu X, Liu Q. Evaluation of recombinant granule antigens GRA1 and GRA7 for serodiagnosis of Toxoplasma gondii infection in dogs. BMC Vet Res 2014; 10: 1-6. https://doi.org/10.1186/1746-6148-10-158

11. Khanaliha K, Motazedian MH, Kazemi B, Shahriari B, Bandehpour M, Sharifniya Z. Evaluation of recombinant SAG1, SAG2, and SAG3 antigens for serodiagnosis of toxoplasmosis. Korean J Parasitol 2014; 52: 137-142. https://doi.org/10.3347/kjp.2014.52.2.137

12. Ferra B, Holec-Gąsior L, Grąźlewska W. Toxoplasma gondii recombinant antigens in the serodiagnosis of toxoplasmosis in domestic and farm animals. Animals 2020; 10: 1245. https://doi.org/10. 3390/ani10081245

13. Gatkowska J, Dziadek B, Brzostek A, Dziadek J, Dzitko K, Długońska H. Determination of Toxoplasma gondii Recombinant ROP2 and ROP4 Antigens Diagnostic Value on Mouse Experimental Model. Pol J Microbiol 2010; 59: 137-141. https://doi. org/10.33073/pjm-2010-022

14. Grzybowski MM, Gatkowska JM, Dziadek B, Dzitko K, Długońska H. Human toxoplasmosis: a comparative evaluation of the diagnostic potential of recombinant Toxoplasma gondii ROP5 and ROP18 antigens. J Med Microbiol 2015; 64: 12011207. https://doi.org/10.1099/jmm.0.000148

15. Lee SH, Lee DH, Piao Y, Moon EK, Quan FS. Influenza M1 viruslike particles consisting of Toxoplasma gondii rhoptry protein 4 . Korean J Parasitol 2017; 55: 143-148. https://doi.org/10.3347/ kjp.2017.55.2.143

16. Kang HJ, Lee SH, Kim MJ, Chu KB, Lee DH, Chopra M, Choi HJ, Park H, Jin H, Quan FS. Influenza virus-like particles presenting both Toxoplasma gondii ROP4 and ROP13 Enhance Protection against T. gondii infection. Pharmaceutics 2019; 11: 342. https:// doi.org/10.3390/pharmaceutics11070342

17. Lee SH, Kim AR, Lee DH, Rubino I, Choi HJ, Quan FSF. Protection induced by virus-like particles containing Toxoplasma gondii microneme protein 8 against highly virulent RH strain of Toxoplasma gondii infection. PLoS One 2017; 12: e0175644. https:// doi.org/10.1371/journal.pone.0175644

18. Drinić M, Wagner A, Sarate P, Zwicker C, Korb E, Loupal G, Peschke R, Joachim A, Wiedermann U, Schabussova I. Toxoplasma gondii tachyzoite-extract acts as a potent immunomodulator against allergic sensitization and airway inflammation. Sci Rep 2017; 7: 1-12. https://doi.org/10.1038/s41598-017-15663-4

19. Kang HJ, Chu KB, Lee DH, Lee SH, Park BR, Kim MC, Kang SM, Quan FS. Influenza M2 virus-like particle vaccination enhances protection in combination with avian influenza HA VLPs. PLoS One 2019; 14: e0216871. https://doi.org/10.1371/journal.pone. 0216871

20. Lee SH, Chu KB, Kang HJ, Quan FS. Virus-like particles containing multiple antigenic proteins of Toxoplasma gondii induce memory $\mathrm{T}$ cell and B cell responses. PLoS One 2019; 14: e0220865. https:// doi.org/10.1371/journal.pone.0220865

21. Roozbehani M, Falak R, Mohammadi M, Hemphill A, Razmjou E, reza Meamar A, Masoori L, Khoshmirsafa M, Moradi M, Gharavi MJ. Characterization of a multi-epitope peptide with selective MHC-binding capabilities encapsulated in PLGA nanoparticles as a novel vaccine candidate against Toxoplasma gondii infection. Vaccine 2018; 36: 6124-6132. https://doi.org/10.1016/j.vaccine.2018. 08.068

22. Rahimi MT, Sarvi S, Sharif M, Abediankenari S, Ahmadpour E, Valadan R, Fasihi-Ramandie M, Hosseini S, Daryani A. Immunological evaluation of a DNA cocktail vaccine with co-delivery of calcium phosphate nanoparticles (CaPNs) against the Toxoplasma gondii RH strain in BALB/c mice. Parasitol Res 2017; 116: 609-616. https://doi.org/10.1007/s00436-016-5325-6

23. Montoya JG. Laboratory diagnosis of Toxoplasma gondii infection and toxoplasmosis. J Infect Dis 2002; 185 (suppl): 73-82. https:// doi.org/10.1086/338827

24. Elsheikha HM, Marra CM, Zhu XQ. Epidemiology, pathophysiology, diagnosis, and management of cerebral toxoplasmosis. Clin Microbiol Rev 2020; 34: e00115-19. https://doi.org/10.1128/ CMR.00115-19

25. Abdelbaset AE, Alhasan H, Salman D, Karram MH, Rushdi MAE, Xuenan X, Igarashi M. Evaluation of recombinant antigens in combination and single formula for diagnosis of feline toxoplasmosis. Exp Parasitol 2017; 172: 1-4. https://doi.org/10.1016/ j.exppara.2016.11.003

26. Munoz M, Liesenfeld O, Heimesaat MM. Immunology of Toxoplasma gondii. Immunol Rev 2011; 240: 269-285. https://doi. org/10.1111/j.1600-065X.2010.00992.x

27. Ferra B, Holec-Gąsior L, Kur J. Serodiagnosis of Toxoplasma gondii infection in farm animals (horses, swine, and sheep) by enzymelinked immunosorbent assay using chimeric antigens. Parasitol 
Int 2015; 64: 288-294. https://doi.org/10.1016/j.parint.2015.03.004

28. Johnson AM, McDonald PJ, Neoh SH. Kinetics of the growth of Toxoplasma gondii (RH strain) in mice. Int J Parasitol 1979; 9: 5556. https://doi.org/10.1016/0020-7519(79)90066-3

29. Holec-Gąsior L, Ferra B, Grąźlewska W. Toxoplasma gondii tetravalent chimeric proteins as novel antigens for detection of specific immunoglobulin g in sera of small ruminants. Animals 2019; 9: 1146. https://doi.org/10.3390/ani9121146

30. Villavedra M, Rampoldi C, Carol H, Baz A, Battistoni JJ, Nieto A. Identification of circulating antigens, including an immunoglobulin binding protein, from Toxoplasma gondii tissue cyst and tachyzoites in murine toxoplasmosis. Int J Parasitol 2001; 31: 2128. https://doi.org/10.1016/S0020-7519(00)00152-1

31. Kim MJ, Lee SH, Kang HJ, Chu KB, Park H, Jin H, Moon EK, Kim SS, Quan FS. Virus-like particle vaccine displaying Toxoplasma gondii apical membrane antigen 1 induces protection against $T$. gondii
ME49 infection in mice. Microb Pathog 2020; 142: 104090. https:// doi.org/10.1016/j.micpath.2020.104090

32. Lee DH, Lee SH, Kim AR, Quan FS. Virus-like nanoparticle vaccine confers protection against Toxoplasma gondii. PLoS One 2016; 11: e0161231. https://doi.org/10.1371/journal.pone.0161231

33. Kikuchi T, Furuta T, Kojima S. Kinetics of the nucleoside triphosphate hydrolase of Toxoplasma gondii in mice with acute and chronic toxoplasmosis. Ann Trop Med Parasitol 2002; 96: 35-41. https://doi.org/10.1179/000349802125000493

34. Picchio MS, Sánchez VR, Arcon N, Soto AS, Perrone Sibilia M, Aldirico MLA, Urrutia M, Moretta R, Fenoy IM, Goldman A, Martin V. Vaccine potential of antigen cocktails composed of recombinant Toxoplasma gondii TgPI-1, ROP2 and GRA4 proteins against chronic toxoplasmosis in C3H mice. Exp Parasitol 2018; 185: 62-70. https://doi.org/10.1016/j.exppara.2018.01.006 